\title{
LECTINAS DE SEMENTES COMO MARCADORES TAXÔNOMICOS DA TRIBO DIOCLEAE
}

\author{
José Tadeu Abreu de Oliveira' \\ Benildo Sousa Cavada' \\ Jorge Luiz Martins ${ }^{2}$ \\ João André Jarenkow ${ }^{2}$ \\ Ilka Maria Vasconcelos ${ }^{1}$ \\ Renato de Azevedo Moreira'
}

\begin{abstract}
RESUMO - Eletroforese em gel de poliacrilamida das proteínas solúveis extraídas de sementes de doze espécies da tribo Diocleae, apresenta padrão qualitativo semethante no que diz respeito às bandas correspondentes às lectinas, sugerindo a possibilidade de seu uso como marcadores taxonômicos.
\end{abstract}

Palavras-chave: Lectinas, taxonomia, Canavalia, Dioclea.

ABSTRACT - Polyacrylamide gel electrophoresis of the soluble proteins extracted from seeds of twelve species belonging to the tribe Diocleae showed substantive qualitative pattern similiarities between the bands correspondent to the lectins.

Key words: Lectins, taxonomy, Canavalia, Dioclea.

\section{Introdução}

A tribo Diocleae, da família das Leguminosas, possui oito gêneros englobando mais de 100 espécies (Harborne et al., 1971). Suas sementes têm morfologia diversificada e apresentam dentre suas proteínas uma classe que se distingue por mediar a aglutinação de hemácias de vários animais (Hague, 1975; Moreira e Cavada, 1984; De Oliveira et al., 1990). Esta atividade biológica é inibida pelos açúcares simples como manose, glicose e seus derivados, sendo estas proteínas, portanto, classificadas como lectinas (Kocourek e Horejsi, 1983). Quando purificadas por cromatografia de afinidade em coluna de Sephadex G-50 e submetidas a eletroforese em gel de poliacrilamida na

1 - Depto. de Bioquímica e Biologia Molecular - Centro de Ciências, Universidade Federal do Ceará - Caixa Postal 1065, CEP 60001, Fortaleza, Ceará.

2 - Departamento de Química Analítica e de Botânica - Universidade Federal de Pelotas - Campus da UFPel, CEP 96100, Pelotas, Rio Grande do Sul. 
presença de dodecil sulfato de sódio (SDS), apresentam três bandas características de pesos moleculares aparentes de 12,18 e 26 KDaltons, respectivamente (Hague, 1975; Moreira e Cavada, 1984; De Oliveira et al., 1990).

Embora a função fisiológica destas proteínas seja desconhecida, estudos acerca do seu metabolismo durante a germinação das sementes têm sugerido que elas desempenham papel importante durante o estabelecimento da planta (Kocourek e Horejsi,, 1983) e testes imunoquímicos têm demonstrado uma grande semelhança entre elas. Analisados conjuntamente, estes dados acima indicam que durante a evolução das espécies pertencentes à tribo Diocleae poucas modificações a nível molecular ocorreram com estas lectinas. A lectina extraída de sementes de Dioclea grandiflora, por exemplo, apresenta cerca de $78 \%$ de homologia no que diz respeito a sua estrutura primária comparada com a Con A, a lectina extraída de sementes de Canavalia ensiformis (Richardson et al., 1984). No presente trabalho o padrão eletroforético apresentado pelas lectinas de várias espécies da tribo Diocleae foi examinado com a finalidade de se verificar se as lectinas presentes nessas sementes podem ser usadas como marcadores taxonômicos.

\section{Material e Métodos}

Sementes foram coletadas em várias regiões do Estado do Ceará, Brasil e classificadas pelo setor de taxonomia vegetal do Departamento de Biologia da Universidade Federal do Ceará.

Preparação das amostras. As farinhas foram preparadas triturando-se as sementes, desprovidas de seus tegumentos, em moinho de café marca Krups 50. Amostras de farinha $(10 \mathrm{mg})$ de 7 espécies do gênero Canavalia e de 5 espécies do gênero Dioclea, ou das lectinas $(2 \mathrm{mg})$ de Canavalia brasilensis e Dioclea grandiflora purificadas como já descrito anteriormente (Moreira e Cavada, 1984; Moreiraet al., 1983) foram tratadas com 1,0 ml de tampão fos-

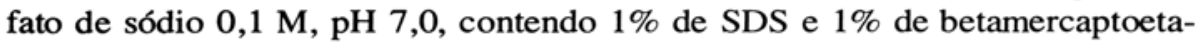
nol e incubadas a $100^{\circ} \mathrm{C}$ por 10 minutos. A suspensão foi centrifugada a 5000 $\mathrm{x} \mathrm{g}, \mathrm{a} 4^{\circ} \mathrm{C}$ por 20 minutos e os sobrenadantes, após adição de sacarose (10\%) e azul de bromofenol (1\%) foram usados para a eletroforese das proteínas.

Eletroforese. A eletroforese foi desenvolvida em gel de poliacrilamida de acordo com método já descrito (Laemmli, 1970). O gel de aplicação continha acrilamida a $3,95 \%$ e o gel de corrida a $17,6 \%$. A corrente aplicada foi de 25 $\mathrm{mA}$ durante 5 horas. As bandas de proteínas foram evidenciadas por coloração com “Coomassie Brilliant Blue R-250” (Laemmli, 1970).

\section{Resultados e Discussão}

Os resultados das eletroforeses das proteínas extraídas das farinhas das sete espécies do gênero Canavalia (C. brasiliensis, C. ensiformis, C. gladia- 


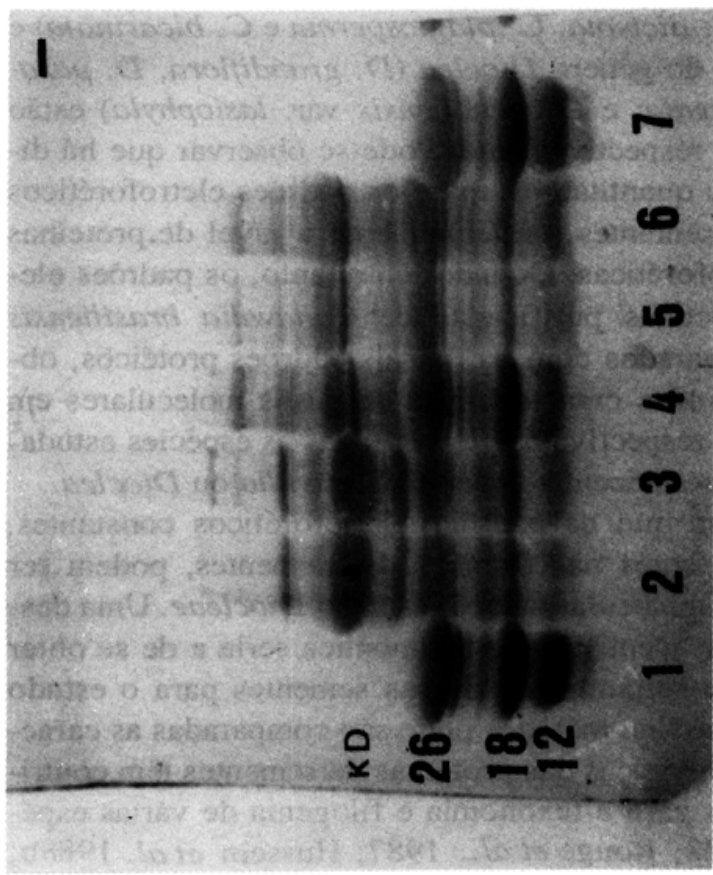

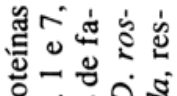

영

प ธั

ثิ 온

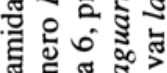

可

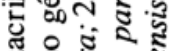

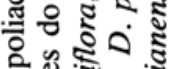

\%马

ชषั

ब्र के क्षे

สำ ํํำ

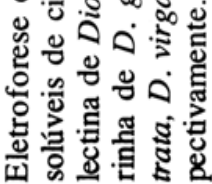

I

范
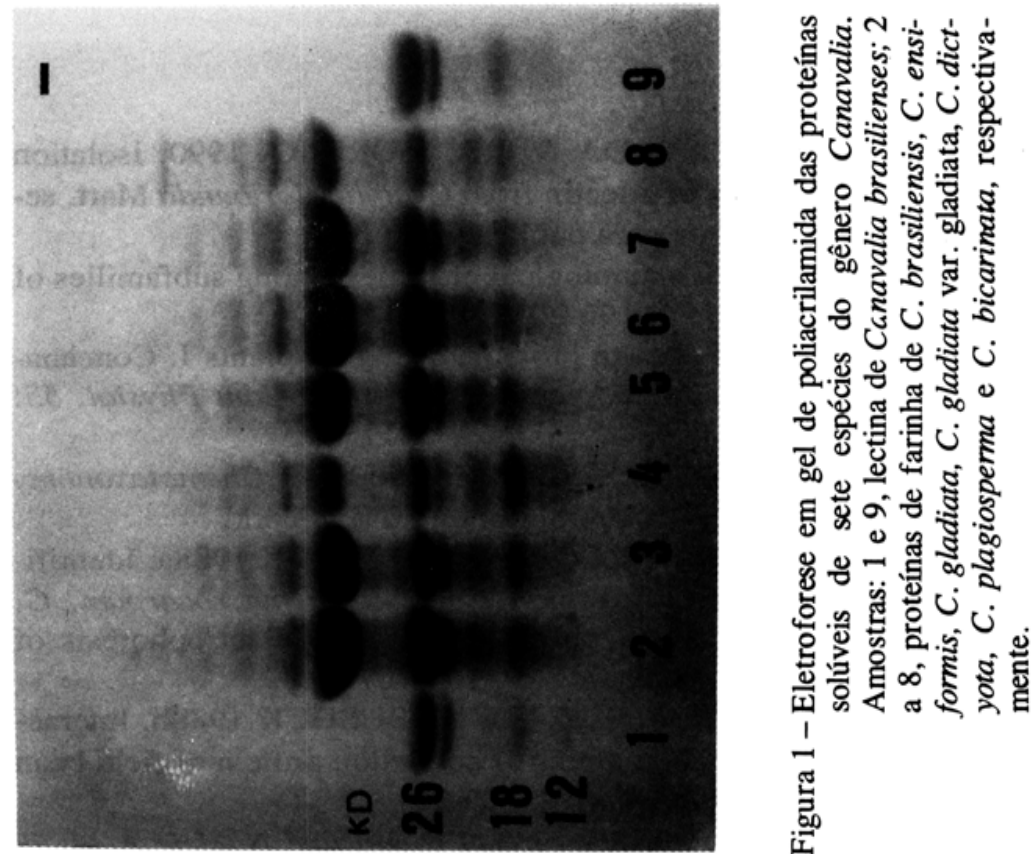
ta, C. gladiata var. gladiata, C. dictyota, C. plagiosperma e C. bicarinata) e das farinhas das cinco espécies do gênero Dioclea ( $D$. grandiflora, D. paraguariensis, D. rostrata, D. virgata, e D. Guianensis var. lasiophyla) estão apresentados nas Figuras 1 e 2, respectivamente. Pode-se observar que há diferenças tanto qualitativas como quantitativas entre os padrões eletroforéticos apresentados pelos vários representantes, principalmente a nível de proteínas com menores mobilidades eletroforéticas. Quando, entretanto, os padrões eletroforéticos obtidos para as lectinas purificadas de Canavalia brasiliensis e Dioclea grandiflora são comparados com os demais padrões protéicos, observa-se a presença das três bandas características de pesos moleculares em torno de 12,18 e $26 \mathrm{KDaltons,} \mathrm{respectivamente,} \mathrm{em} \mathrm{todas} \mathrm{as} \mathrm{espécies} \mathrm{estuda-}$ das, independentemente se elas pertencem ao gênero Canavalia ou Dioclea.

Estas observações sugerem que os padrões eletroforéticos constantes, apresentados pelas lectinas presentes nas farinhas das sementes, podem ser usados como uma característica molecular dentro da tribo Diocleae. Uma desvantagem deste procedimento de identificação taxonômica seria a de se obter plantas já frutificando, de onde seriam coletadas as sementes para o estudo (Hussain et al., 1988a). Mesmo assim, métodos onde são comparadas as características físico-químicas e imunológicas das proteínas de sementes têm contribuído com valiosas informações para a taxonomia e filogenia de várias espécies (Jensen e Fairbrothers, 1983; Rouge et al., 1987; Hussein et al. 1988b; Esen e Hilu, 1989).

\section{Referências Bibliográficas}

DE OLIVEIRA, J.T.A., B.S. CAVADA \& R.A. MOREIRA 1990. Isolation and partial characterization of a lectin from Cratylia floribunda Mart. seeds. Rev. Brasil. Bot., (aceita para publicação).

ESEN, A. \& K.W. HILU 1989. Immunological affinities among subfamilies of the Poaceae. Amer. J. Bot. 76: 196-203.

HAGUE, D.R. 1975. Studies of storage proteins of higher plants I. Concanavalin A from three species of the genus Canavalia. Plant Physiol. 55: 636-642.

HARBORNE, J.B., D. BOULTER \& B.L. TURNER 1971. Chemotaxonomy of the Leguminosae. Academica Press, London, New York.

HUSSAIN, A., H. RAMIREZ, W.M. ROCA, \& W. BUSHUK 1988a. Identification of cultivars of pasture legumes (Centrosema macrocarpum, C. pubescens and $C$. sp.n) by acid polyacrylamide gel electrophoresis of cotyledon storage proteins. Euphytica 39: 105-107.

HUSSAIN, A., H. RAMIREZ, W.M. ROCA \& W. BUSHUK 1988b. Interaccession variation of electrophoregrams of cotyledon protein of field bean (Phaseolus Vulgaris L.). Euphytica 39: 109-111.

JENSEN, U. \& D.E. FAIRBROTHERS 1983. Protein and Nucleic Acids in 
Plant Systematics. Spring-Verlag, New York.

KOCOUREK, J. \& V. HOREJSI 1983. A note of the recent discussion of definition of the term "lectin". In T.C. Bog-Hansen \& G.A. Splengler, eds. Lectins: Biology, Biochemistry, Clinical Biochemistry, vol. 3, pp 3-6, Walter de Gruyter, Berlim.

LAEMMLI, U.K. 1970. Cleavage of structural proteins during the assembly of the bacteriophage t4. Nature 227: 680-685.

MOREIRA, R.A. \& B.S. CAVADA 1984. Lectin from Canavalia brasiliensis (Mart.). Isolation, characterization and behaviour during germination. Biol. Plant. 26: 113-120

MOREIRA, R.A., A.C.H. BARROS, J.C. STEWART \& A. PUSZTAI 1983. Isolation and characterization of a lectin from the seeds of Dioclea grandiflora Mart. Planta 158: 63-70.

RICHARDSON, M., F.A.P. CAMPOS, R.A. MOREIRA, I.L. AINOUZ, R. BEGBIE, W. WATT \& A. PUSZTAI 1984. The complete amino acid sequence of the major alpha-subunit of the lectin from the seeds of Dioclea grandiflora (Mart.). Eur. J. Biochem., 144:101-111.

ROUGE, P., M. RICHARDSON, A. YARWOOD, \& B.S. CAVADA 1987. Single and two chain legume lectins as phylogenetic markers of speciation., Biochem. System. Ecol., 15: 341-348. 